\title{
Mental disorders seek space at the global health table
}

Published at www.cmaj.ca on Oct. 19

$\mathrm{T}$ here's no question that it is very much the neglected child of the global health scene.

In fact, in the US\$22-billion-per-year industry of global health programming, there is nary an international initiative aimed at redressing the enormous toll that mental disorders take on the world's population - causing one million suicides each year alone, according to the World Health Organization (WHO).

In a clearly orchestrated campaign, representatives of the mental health community stepped up to the microphones in session after session of the World Health Summit in Berlin, Germany, to basically say "What about mental health?" while pitching for its inclusion on the agenda, particularly in any form of global fund to be created as part of the 2011 Summit on Non-Communicable Diseases that the United Nations has convened.

"There's definitely a grassroots effort and I think reasonably so," says Dr. Thomas Insel, director of the United States National Institute of Mental Health, one of 27 falling under the US National Institutes of Health umbrella. "Many people in this community feel that they are still not at the table in the way that they'd like to be, particularly given the WHO numbers on disability. They keep thinking, 'What are we, chopped liver? Why are we not part of this conversation?"'

And given that so many of the world's young fall victim to mental disorders, they are "the chronic diseases of young people," Insel adds. "So there's every reason for us to be thinking about global burdens, thinking about what needs to be done, from both the national and international perspective."

Insel joined the brigade during the summit's wrap-up press conference, arguing that mental disorders are a muchneglected "big killer" on the global stage.

The one million suicides around the globe each year are "more than the

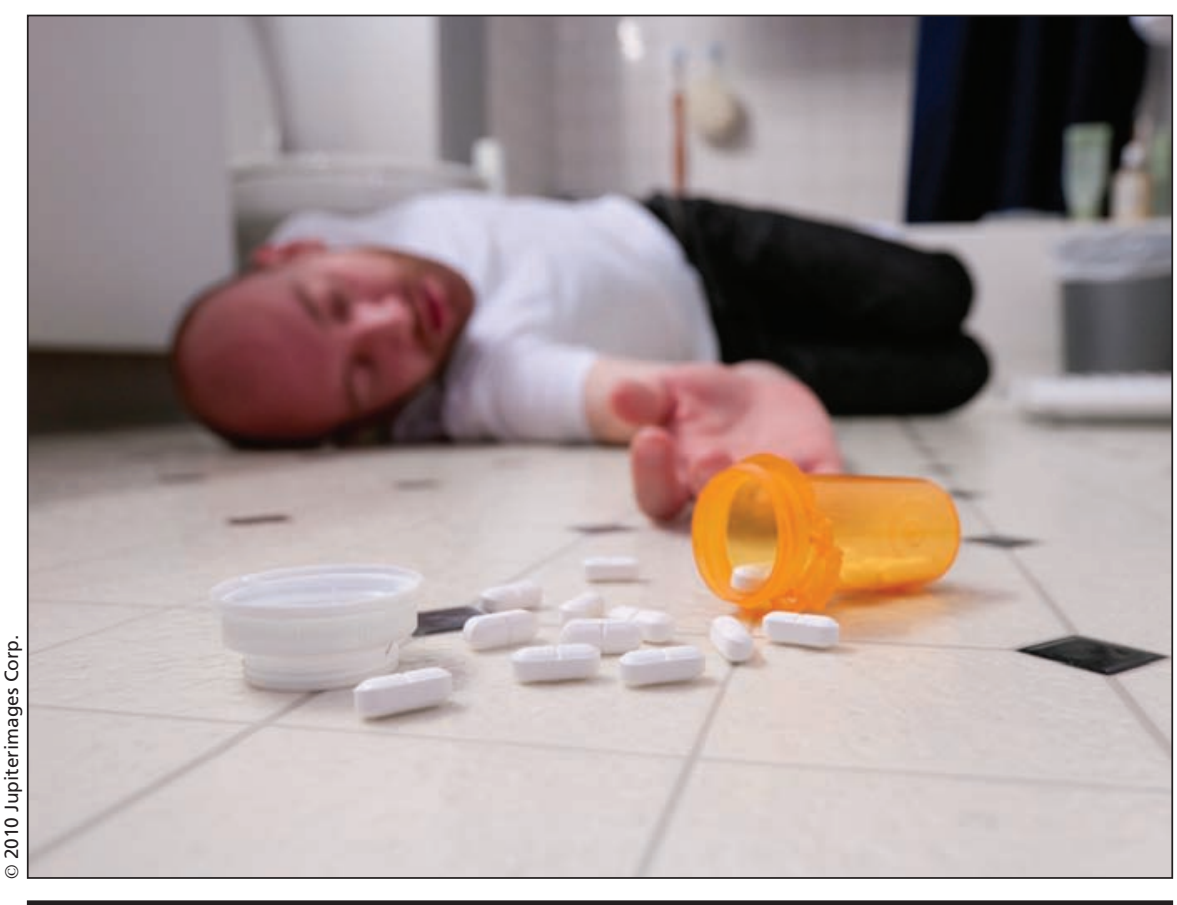

Mental health disorders take an enormous toll on the world's population - responsible for about one million suicides each year, according to the World Health Organization.

number of deaths from auto accidents," he said, adding that death from suicide also outstrips homicide "by two to one."

The world health community has an "enormous opportunity" to put a dent into the toll exacted by suicide, depression, anxiety, schizophrenia, autism and other mental disorders, Insel argued. "The good news is that we have real treatments" for the millions of people in great need, who are stigmatized, or placed in hospitals, prisons and asylums where they do not receive treatment.

Insel later sought to make the concrete, scientific case for mental health at a summit session on "Translation, Transition, Transformation in Psychiatric Research," sketching the basic parameters and principles of his institute's plan to accelerate the development of new personalized interventions for mental disorders by using molecular, diagnostic, proteomic and neuroimaging techniques and tools that have transformed other disciplines over the past decade (see the Institutecommissioned report, From Discovery to Cure: accelerating the development of a new personalized interventions for mental illness, at www.nimh.nih .gov/about/advisory-boards-and-groups /namhe/reports/fromdiscoverytocure .pdf, and the institute strategic plan at www.nimh.nih.gov/about/strategic -planning-reports/nimh-strategic-plan -2008.pdf).

Yet, as they often were at other summit sessions, delegates and even other panelists, appeared skeptical.

Even the concept of mental health "remains poorly defined and lacks a solid scientific basis," said panelist Dr. Hans-Ulrich Wittchen, chairman and director of the Institute of Clinical Psychology and Psychotherapy and the Centre of Clinical Epidemiology and Longitudinal Studies at the Technical University of Dresden in Germany.

An American delegate argued that "there is no other area of global public health where the information is as weak." 
Asked point-blank why mental health should be added to the global health agenda given its evidentiary and definitional conflicts, Wittchen said: "That's a good question. (I can't answer it). How could I? I'm on the other side. I'm part of the problem."

Yet, it begs another question: What kind of evidence-based programs could the community bring to the global health table that could be easily introduced in the developing world? tions.

Insel says there are proven interven-

"Some of this is not rocket science," he says. In the case of suicide, for example, "if you can limit access to firearms amongst people who are at risk, that makes a difference. Putting ledges on bridges, that makes a difference. There are things that we know about that don't get done, and not consistently."

But comprehensive suicide prevention or other mental health programs that could be modified into a global initiative are altogether rare. While the United Kingdom has a national suicide prevention program, it's only two years old and hasn't been evaluated.

Insel says the US has a national suicide prevention strategy but it is dated (2001) and features few concrete programs. But in September, an exercise was launched to "revitalize" it, largely as a consequence of a "shocking" US Department of Defence report that indicated "more soldiers were lost to suicide than to combat over the last five years" (http://usarmy.vo.llnwd.net/e1/HPRRSP /HP-RR-SPReport2010_v00.pdf).

"It's been, for all of us, a huge wakeup call" as most of the soldiers who committed suicide did so "prior to deployments" in either Iraq or Afghanistan, Insel says. "We don't know what the explanation is."

Roughly 34000 Americans commit suicides annually and the intent of the review exercise is to develop an "action agenda that actually puts prevention initiatives on the ground, where the greatest needs are."

"Most of the time that this works well is when it is targeted, when you have a population at risk and you go through awareness messages, as well as through both a public health approach, which is to say 'Let's make sure that access is limited, when we can,' and then, through a more targeted approach, to say, "Who are we most concerned about?"," Insel adds. "We know that someone who ends up in an emergency room with a suicide attempt has a very, very high risk of dying of suicide subsequently. So $50 \%$ of people will make yet another attempt. So that's a group we can go after and follow up. But I have to tell you that, in the United States, we have not done that successfully. And those are the kinds of things that we know how to do." - Wayne Kondro, CMAJ

DOI:10.1503/cmaj.109-3703 